\title{
Role of vitamins in cardiovascular health and disease
}

\author{
This article was published in the following Dove Press journal: \\ Research Reports in Clinical Cardiology \\ 24 October 2014 \\ Number of times this article has been viewed
}

\section{Balazs Debreceni ${ }^{1}$ Laszlo Debreceni ${ }^{2}$}

'Department of Biochemistry and Medical Chemistry, University of Pécs, Medical School, Pécs, Hungary; ${ }^{2}$ Heart Disease Research Foundation, Brooklyn, NY, USA
Correspondence: Balazs Debreceni Department of Biochemistry and Medical Chemistry, University of Pécs, Medical School, Szigeti Street 12, $\mathrm{H}-7624$ Pécs, Hungary

Tel +3672536276

Fax +36 72536277

Email balazs.debreceni@aok.pte.hu
Abstract: Cardiovascular disease (CVD) is the leading cause of mortality around the world. The prevention of CVD is a main goal of health care. Vitamins, especially those with antioxidant potency, may have a role in the prevention of and therapy for CVD. Antioxidant vitamins, vitamin $\mathrm{C}$, vitamin $\mathrm{E}$, and carotenoids are able to decrease the rate of oxidative stress, which may have a principal role in the pathogenesis of atherosclerosis and CVD. Vitamin $\mathrm{B}_{6}$, vitamin $\mathrm{B}_{12}$, and folic acid, as well as vitamin $\mathrm{D}$, also contribute to maintenance of cardiovascular health and can induce cardioprotective effects. Although most of the randomized controlled trials on vitamins failed to show the benefit of vitamin supplementation for cardiovascular outcomes, a number of observational and cohort studies, meta-analyses, and stratified analyses of large vitamin trials appeared to show an effect in some aspects of cardiovascular prevention. Moreover, many of the vitamin trials for secondary prevention are biased by use of vitamins and drugs effective for cardiovascular prevention; therefore, the conclusions drawn from them supporting the effectiveness of vitamin substitution for the prevention of CVD may be inappropriate. To summarize, there are abundant data suggesting the role of vitamins in cardiovascular health and in the primary prevention of CVD; however, examinations using new concepts and new study designs are needed to establish the effectiveness of vitamin supplementation in the therapy for and prevention of CVD.

Keywords: vitamin C, vitamin E, vitamin D, B vitamins, folic acid, cardiovascular disease, cardiovascular prevention

\section{Introduction}

Cardiovascular disease (CVD) is a major public health problem and the leading cause of mortality around the world. Development of CVD leads to a decline of quality of life. Therefore, prevention, particularly primary prevention of CVD, is one of the most important aims of health care. Since atherosclerosis constitutes the basis of CVD, elimination of the modifiable risk factors of atherosclerosis - cigarette smoking, hypertension, diabetes, obesity, elevated level of cholesterol and homocysteine (HCY), stress, overconsumption of alcohol, and lack of physical exercise - and the maintenance of a healthy lifestyle, including stress management and healthy eating with satisfactory vitamin supply, comes into consideration in the prevention of atherosclerosis and CVD. Regarding the cardiovascular system, beriberi was the first illness where the deficiency of a vitamin - vitamin $B_{1}$ - has been shown as the principal cause of pathological symptoms in the heart and vascular system.

The vitamins related to the cardiovascular system and cardiovascular health may be investigated from two points of view. A suitable and efficient supply of all 
vitamins is essential to normal life and the normal functions of the cells and organs. On the other hand, there are vitamins which, beyond their primary role, may also have important roles in both the prevention of and therapy for CVD and other diseases. This group includes antioxidant vitamins (vitamin C, vitamin E, and carotenoids), folic acid (FA), vitamins $\mathrm{B}_{6}$ and $\mathrm{B}_{12}$ from the vitamin $\mathrm{B}$ group, vitamin $\mathrm{D}$, and coenzyme $\mathrm{Q}_{10}$. The main question to be addressed is whether vitamins ingested above physiological needs as defined by the recommended dietary intake, ie, vitamin substitution therapy, have benefit in cardiovascular prevention (CVP) and/or therapy of CVD. This question is very important and should be urgently addressed, because if the benefit of vitamin substitution therapy can be proven, substitution therapy could be a cheap and easy way to decrease the occurrence of CVD events.

A number of publications suggest that vitamins are capable of improving the function of the heart and vessels. On the other hand, many contradictions and inconsistent results cause conflicts because of the very abundance of data produced. In vitro investigations, animal experiments, and clinical examinations suggest the beneficial effects of vitamins in the inhibition of atherogenesis and atherosclerosis progression. Moreover, the results of observational and cohort studies, and some clinical trials have shown the benefit of vitamin supplementation. However, most large randomized controlled trials (RCTs) could not prove the effectiveness of vitamins in CVP. In spite of the benefits shown in observational and cohort studies, vitamin substitution therapy has been ruled out and neglected due to the results of large vitamin trials, which have been considered to be "negative". However, in the last 5 years, many of these "negative trials" have been revised, and since the results of revised subgroup and stratified analyses revealed the efficacy of vitamins in some aspects of prevention, vitamins may not be claimed as "without effects" any more. The results of meta-analyses of large vitamin trials and studies also showed the role of vitamin substitution in the prevention of CVD. It appears that the assessment of vitamin substitution is changing, although official guidelines still do not support the introduction of vitamin substitution for CVP. ${ }^{1}$ Publications of the last few years also revealed that the results of large vitamin trials might have been biased by confounding factors. For this reason, the conclusions drawn from them may be inappropriate. In this review, we investigate the role of vitamins and vitamin substitution in cardiovascular health and their possible roles in therapy for CVD, and CVP.

\section{Role of antioxidant vitamins in CVP}

First, we examine the relationship between antioxidant vitamins (vitamin $\mathrm{C}$, vitamin $\mathrm{E}$, and carotenoids) and the pathogenesis, therapy, and prevention of CVD. Considering the concept of oxidative stress and the biochemical aspects of antioxidants and antioxidant vitamins, we refer the reader to comprehensive reviews. ${ }^{2,3}$ Oxidative stress results from an imbalance between oxidants and antioxidants where oxidants are in excess of antioxidants. The oxidative stress generated by reactive oxygen species - eg hydrogen peroxide $\left(\mathrm{H}_{2} \mathrm{O}_{2}\right)$, and the free radicals superoxide $\left(\mathrm{O}_{2}{ }^{--}\right)$ and hydroxyl radical $\left(\mathrm{HO}^{\circ}\right)$ - and reactive nitrogen species, such as peroxynitrite $\left(\mathrm{ONOO}^{-}\right)$, plays a central role in the pathogenesis of CVD. ${ }^{2,3}$

When investigating the relationship between CVD and antioxidant vitamins, it should be taken into account that pathological changes leading to CVD develop in the endothelial cell line. The endothelium is not only the "wallpaper" of the vasculature, but the endothelial cells also communicate with all of the circulating cells and participate in the regulation of their behavior. An intact endothelium is the prerequisite for normal functioning of the vascular system. According to the contemporary view, ${ }^{4-6}$ atherogenesis originates from endothelial dysfunction caused by oxidative damage of the endothelial cells. Oxidative stress-induced injury of endothelial cells by free radicals is associated with inflammatory processes that lead to production of various cytokines, which participate in inflammatory reactions through the activation of inflammatory mediators. ${ }^{4-6}$ Oxidative stress activates the transcription factor nuclear factor- $\kappa \mathrm{B}(\mathrm{NF} \kappa \mathrm{B})$ through superoxide, and induces the expression of inflammatory mediators involved in inflammation of the vessel wall. ${ }^{7}$

Antioxidant vitamins are in close association with cardiovascular health, and are also implicated in ameliorating cardiovascular disorders. Abundant data suggest a role of antioxidant vitamins in the normal functioning of the heart and the vascular system. The role of antioxidant vitamins in maintaining cardiovascular health is dual: they have a preventive potential and also a therapeutic effect, because they are able to cure pathological disturbances of the cardiovascular system by inhibiting oxidative stress.

\section{Clinical research suggesting antioxidant vitamins' beneficial effects in CVP}

The effects of antioxidant vitamins have been investigated in clinical trials and studies with dietary supplementation of vitamin $\mathrm{C}$, vitamin $\mathrm{E}$, and carotenoids. The findings obtained 
from these trials and studies on the role of antioxidant vitamins in CVD prevention and therapy are inconclusive. In addition to the trials and studies considered "negative", there are "successful" trials and studies, where antioxidant vitamins had beneficial effects in the prevention of CVD.

Cohort studies conducted 20 years ago already suggested the role of vitamins in CVP. In a study by Stampfer et $a l,{ }^{8}$ in which 87,245 female nurses free from CVD were followed up for 8 years, vitamin $\mathrm{E}$ intake reduced the risk of coronary heart disease (CHD) by 34\%. In a cohort study, ${ }^{9}$ 16-year follow-up of female nurses showed an inverse association between intake of vitamin $\mathrm{C}$ and risk of CHD, with a $27 \%$ risk reduction. In the European Prospective Investigation into Cancer and Nutrition study, ${ }^{10}$ plasma vitamin $\mathrm{C}$ concentration was inversely associated with the risk of heart failure in 10,299 subjects. According to this study, plasma levels of vitamin $\mathrm{C}$ may predict the incidence of heart failure. There was also a strong association between blood pressure and plasma levels of vitamin C in 20,926 participants. ${ }^{11}$ Subjects with higher vitamin $\mathrm{C}$ plasma levels had lower blood pressure. In a meta-analysis of 29 trials, ${ }^{12}$ short-term supplementation with vitamin $\mathrm{C}$ resulted in a reduction of both the systolic and the diastolic blood pressure $(-4.85 \mathrm{mmHg}$ and $-1.67 \mathrm{mmHg}$, respectively). The median dose of vitamin $\mathrm{C}$ was $500 \mathrm{mg} /$ day, and the median duration of the examination was 8 weeks.

In the Supplementation in Vitamins and Mineral Antioxidants Study (SU.VI.MAX), ${ }^{13}$ the combination of vitamin C, vitamin $\mathrm{E}, \beta$-carotene, selenium, and zinc decreased the risk of ischemic CVD by $11 \%$. Total mortality was also decreased in men by $36 \%$, as a result of 8 years of supplementation. In another study ${ }^{14}$ in 39,910 subjects free of CHD, vitamin E intake (60 IU/day) decreased the risk of CHD by $36 \%$. Men with intake of vitamin E of 100 IU/day for 2 years had a higher reduction in the risk of CHD. In the Cambridge Heart Antioxidant Study (CHAOS), ${ }^{15}$ supplementation with vitamin $E$ reduced the risk of cardiovascular death and nonfatal myocardial infarction (MI) by 47\% (41 versus 64 events).

In the Antioxidant Supplementation in Atherosclerosis Prevention study (ASAP), ${ }^{16}$ a randomized trial, supplementation with vitamin $\mathrm{C}$ and vitamin $\mathrm{E}$ reduced the progression of carotid atherosclerosis by $74 \%$ in men compared with placebo. Also in the ASAP study, ${ }^{17}$ the progression of carotid intima-media thickness (CIMT) was decreased by supplementation with a combination of vitamin $\mathrm{C}$ and vitamin $\mathrm{E}$ during 6-year follow-up in subjects with hypercholesterolemia.

In the Secondary Prevention with Antioxidants of Cardiovascular disease in Endstage renal disease study (SPACE), ${ }^{18}$ a randomized placebo-controlled trial in hemodialysis patients with pre-existing CVD, vitamin E supplementation (800 IU/day) reduced the incidence of CVD endpoints and MI. The Japan Collaborative Cohort Study for Evaluation of Cancer Risk (JACC) ${ }^{19}$ examined the effect of vitamin $\mathrm{C}$ intake on cardiovascular morbidity and mortality after 16.5-year follow-up. An inverse association between vitamin $\mathrm{C}$ intake and morbidity and mortality from stroke, CHD, and CVD was found for women.

Knekt et $\mathrm{al}^{20}$ conducted an analysis of nine prospective studies on the effects of vitamin $\mathrm{C}$, vitamin $\mathrm{E}$, and carotenoids on CHD risk. The analysis included 293,172 subjects who were free of CHD at the start of the vitamin supplementation and who were followed up for 10 years. The results showed that vitamin $\mathrm{C}$ intake of $>700 \mathrm{mg} /$ day decreased the risk of CHD and mortality by $25 \%$ compared with those who went without vitamin $\mathrm{C}$ supplementation.

The Women's Antioxidant Cardiovascular Study $(\mathrm{WACS})^{21}$ was planned to investigate the effects of vitamin $\mathrm{C}$, vitamin $\mathrm{E}$, and $\beta$-carotene on the combined outcome of $\mathrm{MI}$, stroke, coronary revascularization, and CVD death among 8,171 female health professionals at increased risk and with a history of CVD or CVD risk factors. The subjects were followed up for a mean duration of 9.4 years. Despite $26 \%-27 \%$ of the members of all groups being multivitamin users, which might have caused bias, the vitamin $\mathrm{E}$ treatment led to a $21 \%$ decrease of the relative risk (RR) of ischemic stroke and a $20 \%$ decrease of RR for nonfatal stroke. Censoring participants on noncompliance led to a significant $23 \%$ reduction in the primary endpoints, and in the secondary endpoints there was a $22 \%$ reduction in $\mathrm{MI}$, a $27 \%$ reduction in stroke, a $9 \%$ reduction in CVD mortality, and a $23 \%$ reduction in the combination of MI, stroke, and CVD deaths.

Hodis et $\mathrm{a}^{22}$ showed that there was an association between supplementary vitamin E intake and angiographically demonstrated reduction in coronary artery lesion progression. Subjects with supplementary vitamin E intake of 100 IU/day or greater, demonstrated less coronary artery lesion progression than subjects with supplementary vitamin $\mathrm{E}$ intake of less than $100 \mathrm{IU} /$ day. Increased intake of vitamin $\mathrm{C}$ was inversely associated with CIMT progression during 3 years of follow-up. ${ }^{23}$

The key role of oxidative stress in the pathogenesis of post-cardiac surgery atrial fibrillation has been clearly demonstrated. ${ }^{24-28}$ Oxidative stress plays a role in the development of rhythm disturbances in the early postoperative period after coronary artery bypass grafting. Administration of vitamin $\mathrm{C}$ in the first 24 hours after the operation was effective 
in preventing disturbances of cardiac rhythm. ${ }^{29}$ Vitamin $\mathrm{C}$ in combination with $\beta$-blockers significantly reduced the incidence of postoperative atrial fibrillation in patients with bypass grafting surgery compared with the administration of $\beta$-blockers alone. ${ }^{30}$ Supplementation with vitamin $C$ reduced the incidence of post-coronary artery bypass grafting atrial fibrillation, and decreased the time needed for rhythm restoration and length of hospital stay. ${ }^{31}$

\section{Antioxidant vitamin studies seemed to be ineffective in CVP}

In the last decade several clinical trials and studies were conducted that could not show beneficial effects of antioxidant vitamin supplementation in CVD prevention. These trials and studies, which were declared "negative" (ie, finished without effect), are described in this section. The Physicians' Health Study II (PHSII) ${ }^{32}$ examined the effects of vitamin $\mathrm{E}$ and $\mathrm{C}$ supplementation in CVP. According to the conclusions of the trial, "neither vitamin E nor vitamin $\mathrm{C}$ supplementation reduced the risk of major cardiovascular events." ${ }^{32}$ However, the baseline characteristics showed that both in the active (vitamin) and in the placebo group, the percentage of current aspirin users was $77.4 \%$. Aspirin usage may have caused a bias, which may have led to incorrect evaluation of the results. Apart from the possibly biased results, the subgroup analysis showed that the total MI was $13 \%$ less in the vitamin E (active) group compared with the placebo group, and MI deaths were $36 \%$ less in the active group than in the placebo group. Moreover, stroke deaths were $24 \%$ less in the vitamin E group than in the placebo group. Therefore, PHSII should not be considered a "negative" trial.

In the Gruppo Italiano per lo Studio della Sopravvivenza nell'Infarto miocardico (GISSI)-Prevenzione trial, ${ }^{33}$ 11,324 patients with recent MI were supplemented with vitamin $\mathrm{E}$ for 3-5 years. Vitamin $\mathrm{E}$ treatment resulted in beneficial effects for the combined endpoints, cardiovascular death $(\mathrm{RR}=0.80)$, cardiac death $(\mathrm{RR}=0.77)$, coronary death $(R R=0.75)$, and sudden death $(R R=0.65)$, although these results were not expressed in the findings, and in the interpretation one may read that vitamin E supplementation had no benefit.

In the Heart Outcomes Prevention Evaluation (HOPE) and HOPE-The Ongoing Outcomes (HOPE-TOO) trials, ${ }^{34}$ the effect of vitamin E substitution was examined in subjects with angina pectoris, hypertension, hypercholesterolemia, diabetes mellitus, previous MI, stroke, coronary artery bypass graft surgery, and percutaneous coronary intervention. However, the patients had been taking $\beta$-blockers, diuretics, aspirin or antiplatelet agents, lipid-lowering agents, and calcium channel blockers. It is not therefore surprising that vitamin $\mathrm{E}$ supplementation had no further effects beyond that of the medications in this secondary prevention study on cardiovascular outcomes.

The MRC/BHF Heart Protection Study ${ }^{35}$ was a secondary prevention trial. In this trial, 20,536 adults were enrolled. Prior to supplementation they had CVD, or diabetes, or hypertension, and approximately $20 \%$ of the subjects were being treated with simvastatin. Administration of vitamin $\mathrm{E}$, vitamin $\mathrm{C}$, and $\beta$-carotene for 5 years did not produce any significant reduction in mortality, which is not surprising considering the previous pathological background.

In the Women's Health Study (WHS), ${ }^{36} 39,876$ healthy women were randomly assigned to receive vitamin E (600 IU of natural source on alternate days) or placebo, or aspirin or placebo, and were followed up for an average of 10.1 years. From the baseline characteristics, it appeared that multivitamin use was $39.2 \%$ in the active (vitamin) group and 38.4\% in the placebo groups. Therefore, the results might have been biased. Moreover, previous MI had occurred in 13\% and $12.9 \%$ in the vitamin and placebo groups, respectively. The data from this large vitamin trial indicated no benefit for major cardiovascular events; however, cardiovascular death decreased by a significant $24 \%(R R=0.76)$ in the active (vitamin E) group. In the secondary trials and studies performed in subjects after the development of sclerotic plaques, MI, or stroke, where the cardiac/vessel structure has degenerated, preventive effects from antioxidant vitamin supplementation cannot be expected. Antioxidant vitamins may contribute to the prevention of atherogenesis by inhibiting oxidative stress and endothelial dysfunction; therefore, vitamins may be important first of all in primary prevention, but they are not capable of bringing about pharmacological effects to remodel degenerated vessel structure. If vitamin E still shows efficacy in secondary prevention, it is probably due to its antiplatelet activity. Moreover, the effectiveness of antioxidant vitamins in secondary prevention may be related to the inhibition of atherosclerosis progression, which can be observed only in long-term investigation.

The Alpha-Tocopherol, Beta-Carotene Cancer Prevention Study (ATBC) $)^{37-40}$ was primarily designed to obtain data on the incidence of lung cancer in case of $\alpha$-tocopherol and $\beta$-carotene supplementation. The secondary aim was to evaluate the effect on other cancers, all-cause mortality, and CVD in randomized, placebo-controlled trials. In one ATBC publication, Virtamo et $\mathrm{al}^{37}$ investigated the effect of vitamin $\mathrm{E}$ and $\beta$-carotene supplementation on major coronary events 
in 27,271 Finnish male smokers with no history of MI. In this primary prevention trial, major coronary events decreased by $4 \%$, and the incidence of fatal CHD decreased by $8 \%$ among those taking vitamin $\mathrm{E}$, but $\beta$-carotene had no effect. In another placebo-controlled ATBC trial Törnwall et $\mathrm{al}^{38}$ examined the 6-year post-trial effects of $\alpha$-tocopherol (50 $\mathrm{mg} /$ day) and $\beta$-carotene ( $20 \mathrm{mg} /$ day) in 29,133 male smokers. The intervention lasted 5-8 years, and the participants were followed up post trial for 6 years. During vitamin supplementation, the risk of fatal CHD increased by $44 \%$ among those who had been taking $\beta$-carotene compared with those who did not, whereas $\beta$-carotene had no post-trial effect on fatal CHD or nonfatal recurrent MI.

The effect of $\alpha$-tocopherol and $\beta$-carotene supplements on the incidence of stroke and mortality in 28,519 male cigarette smokers without history of stroke was investigated in another ATBC publication. ${ }^{39}$ The median follow-up was 6 years. $\alpha$-tocopherol supplementation increased the risk of subarachnoid hemorrhage but decreased the risk of cerebral infarction. According to the authors' opinion, the effects may be due to the antiplatelet actions of $\alpha$-tocopherol. However, it should be noted that during the use of aspirin the effect of vitamin $\mathrm{E}$ on the incidence of hemorrhagic stroke cannot be assessed, since both aspirin and vitamin $\mathrm{E}$ inhibit platelet aggregation, and there is no information on aspirin use in the publication. Another ATBC trial, by Leppälä et al, ${ }^{40}$ examined the effect of $\alpha$-tocopherol and $\beta$-carotene in 29,133 male smokers. It was established that vitamin E supplementation might prevent ischemic stroke in hypertensive patients.

\section{B vitamins in cardiovascular health}

A number of investigations have indicated the beneficial effects of FA and a vitamin $\mathrm{B}_{6}$ and $\mathrm{B}_{12}$ complex on the cardiovascular system. $B$ vitamins (FA, vitamin $B_{6}$, and vitamin $B_{12}$ ) may play a role in CVP. FA inhibits HCY-induced superoxide production, NFKB activation, and monocyte chemoattractant protein (MCP)-1 expression in macrophages; ${ }^{41}$ thus, FA may attenuate the atherogenicity of HCY investigated in vitro. FA improves endothelial function ${ }^{42,43}$ and endothelial dysfunction, ${ }^{44,45}$ inhibits intracellular superoxide generation, and increases the half-life of nitric oxide (NO). ${ }^{46}$ The vitamin B complex was found to increase flow-mediated endothelium-dependent vasodilation in subjects with hyperhomocysteinemia. ${ }^{47}$ It is well established that FA lowers plasma HCY concentration, ${ }^{48}$ and at the same time, it improves endothelial function. ${ }^{43,49}$ Furthermore, FA also improves endothelial function independently from its HCY-lowering effect. ${ }^{45,50}$ Vitamin $\mathrm{B}_{6}$ is a powerful antioxidant vitamin that can prevent low-density lipoprotein-induced impairment of endothelial cell NO generation. ${ }^{51}$ The cardioprotective effect of FA supplementation has been shown in MI in mice ${ }^{52}$ and rats. ${ }^{53}$ FA plays a role in the regulation of endothelial NO synthase (eNOS) activity, ${ }^{54}$ increases the bioavailability and stabilization of tetrahydrobiopterin (the cofactor of eNOS), and supports eNOS in maintaining its coupled state to generate NO. ${ }^{55}$ eNOS uncoupling, when eNOS is engaged to generate oxygen-based free radicals, plays a major role in the development of CVD..$^{50,54}$

\section{Beneficial effects of B vitamins in CVP}

FA supplementation reduced CIMT and its progress ${ }^{56,57}$ in atherosclerotic subjects, in kidney diseases ${ }^{58}$ including renal transplant recipients, ${ }^{59}$ in chronic hemodialysis patients, ${ }^{60}$ and in cases of increased levels of HCY. ${ }^{61}$

An inverse association has been found between dietary FA intake and the risk of acute coronary events. Low dietary FA intake is associated with an excess incidence of acute coronary events ${ }^{62,63}$ and stroke; ${ }^{63}$ on the other hand, high serum FA concentrations are associated with a reduced incidence of acute coronary events. ${ }^{64}$ Low FA serum levels may be a risk factor of $\mathrm{CVD}^{65}$ and stroke, ${ }^{66}$ and an increased intake of FA has been associated with a decreased risk of MI. ${ }^{67}$ Following the introduction of the FA food fortification program in North America, the incidence of CVD, particularly the events of $\mathrm{MI}^{68}$ and stroke mortality, ${ }^{69}$ decreased.

Rimm et $\mathrm{al}^{70}$ examined the role of FA and vitamin $\mathrm{B}_{6}$ intake on the incidence of nonfatal $\mathrm{MI}$ and fatal CHD in 80,082 women with no previous history of CVD. After 14 years of follow-up, the risk of CHD was reduced by $24 \%$ in women who regularly used multiple vitamins (median intake of FA $0.696 \mathrm{mg} /$ day, vitamin $\mathrm{B}_{6} 4.6 \mathrm{mg}$ /day). Findings from this study indicate that use of low-dose multivitamin supplements may play a role in the primary prevention of MI.

Further studies suggest that FA intake may aid in the primary prevention of MI. A Swedish study, the Stockholm Heart Epidemiology Program (SHEEP) $)^{71}$ found that daily use of multivitamin supplementation (containing $400 \mu \mathrm{g}$ FA) was inversely related to the risk of MI. The findings of SHEEP have been confirmed in a population-based cohort of Swedish women. ${ }^{72}$ In this study, the use of multivitamins (containing $400 \mu \mathrm{g} \mathrm{FA}$ ) was inversely associated with MI, especially for long-term use among women with no previous CVD (31,671 cases). However, this inverse association was not shown in the CVD group (2,262 cases). The reduction of MI risk was $30 \%$ in women with no history of CVD, and for multivitamin use over 5 years the risk reduction reached $41 \%$. 
The Kuopio Ischemic Heart Disease Risk Factor Study (KIHD) ${ }^{62}$ examined the association between dietary intake of FA, vitamin $B_{6}$, and vitamin $B_{12}$ and the risk of acute coronary events. FA intake was split into fifths. It was found that subjects in the highest fifth (level) of FA intake had an RR of acute coronary events of 0.45 compared with those in the lowest fifth. An increased intake of FA has been associated with a decreased risk of ischemic stroke in men. In 43,732 men free of CVD and diabetes at baseline, the intake of FA was associated with a significantly lower risk of ischemic but not hemorrhagic stroke. After 14 years of follow-up, the risk of ischemic stroke decreased by $29 \% .{ }^{62}$

In another study, ${ }^{73}$ increased FA intake was also associated with a decreased risk of ischemic stroke in men. The association of dietary FA, vitamin $\mathrm{B}_{6}$, and vitamin $\mathrm{B}_{12}$ intake with the risk of stroke subtypes was examined among 26,556 male Finnish smokers. ${ }^{74}$ It was found that during a mean follow-up of 13.6 years, a high FA intake was accompanied by a statistically significantly lower risk of cerebral infarction but not intracerebral or subarachnoid hemorrhage.

\section{$B$ vitamin trials which failed to show beneficial effects in CVP}

In spite of the fact that $B$ vitamins could provide an inexpensive and effective method for CVD prevention, the use of $B$ vitamins for the primary prevention was rejected on the basis of the results of recently published, large randomized clinical vitamin trials. We discuss below the trials that did not show the benefit of vitamin B supplementation.

The Norwegian Vitamin Trial (NORVIT) ${ }^{75}$ included 3,749 men and women who had had an acute MI within 7 days before randomization. Subjects in both the placebo and active (vitamin) groups had been taking statins and other drugs. Patients were randomly assigned to treatment with $0.8 \mathrm{mg}$ FA, $0.4 \mathrm{mg}$ vitamin $\mathrm{B}_{12}$, or $40 \mathrm{mg}$ vitamin $\mathrm{B}_{6}$. The primary endpoint during a median follow-up of 40 months was a composite of recurrent MI, stroke, and sudden death attributed to coronary artery disease. Treatment with the three $B$ vitamins in combination did not lower the risk of recurrent CVD after acute MI.

The Study of the Effectiveness of Additional Reductions in Cholesterol and Homocysteine trial (SEARCH), ${ }^{76}$ a double-blind RCT, was done on 12,064 survivors of MI. It showed that $2 \mathrm{mg}$ FA plus $1 \mathrm{mg}$ vitamin $\mathrm{B}_{12}$ daily did not have beneficial effects on vascular outcomes versus matched placebo. The Western Norway B Vitamin Intervention Trial (WENBIT), ${ }^{77}$ also a double-blind RCT, was conducted in two university hospitals in Western Norway. A total of 3,096 adult participants undergoing coronary angiography were randomized. At baseline, 59.3\% had double- or triple-vessel disease, $83.7 \%$ had stable angina pectoris, and $14.9 \%$ had acute coronary syndromes. This trial did not find an effect of treatment with $\mathrm{FA} /$ vitamin $\mathrm{B}_{12}$ or vitamin $\mathrm{B}_{6}$ on total mortality or cardiovascular events.

In the Women's Antioxidant and Folic Acid Cardiovascular Study (WAFACS), ${ }^{67}$ 5,442 female US health professionals with either a history of CVD or three or more coronary risk factors were enrolled in a randomized, double-blind, placebocontrolled trial to receive a combination of FA, vitamin $\mathrm{B}_{6}$, and vitamin $\mathrm{B}_{12}$. After 7.3 years of follow-up, the secondary outcome $\mathrm{MI}$ was reduced $(\mathrm{RR}=0.87$ ), but stroke and CVD mortality were not.

In the Heart Outcomes Prevention Evaluation 2 Study (HOPE 2), ${ }^{78} 5,522$ patients with previous vascular disease or diabetes were treated with $2.5 \mathrm{mg}$ FA, $50 \mathrm{mg}$ vitamin $\mathrm{B}_{6}$, and $1 \mathrm{mg}$ vitamin $\mathrm{B}_{12}$ for an average of 5 years. B vitamin therapy did not reduce the risk of major cardiovascular events (death from cardiovascular causes and MI) in patients with vascular disease. The HOPE 2 Study has been declared "negative", despite a $25 \%$ reduction in stroke risk reported in the results, which has not been included in the conclusions.

In the Homocysteine Study (HOST), ${ }^{79} 2,056$ patients with advanced chronic kidney disease and endstage renal disease received $40 \mathrm{mg} F A, 100 \mathrm{mg}$ vitamin $\mathrm{B}_{6}$, and $2 \mathrm{mg}$ vitamin $\mathrm{B}_{12}$ or placebo. In the case history of the patients, congestive heart failure, angina, MI, coronary artery bypass graft surgery, diabetes, stroke, and percutaneous coronary angioplasty or stenting were indicated. Moreover, prior to vitamin supplementation, patients were treated with lipid-lowering and antiplatelet drugs, aspirin, angiotensin-converting enzyme inhibitors, $\beta$-blockers, and other drugs. During 3.2 years of follow-up, there was no improvement in survival or reduction in the incidence of vascular disease.

\section{B vitamin studies with positive output after meta- or subgroup analysis and stratification}

Many of the "negative" B vitamin studies and trials have been recently subjected to meta-, subgroup, or stratified analyses, which revealed beneficial effects of vitamin supplementation.

In a detailed analysis of the HOPE 2 Study, Saposnik et $\mathrm{a}^{80}$ showed that the positive impact of vitamin therapy on overall stroke risk was most pronounced in subjects aged less than 70 years, in those with untreated hyperlipidemia, in those not receiving antiplatelet medication, and in 
those with hyperhomocysteinemia or residing in a country where FA fortification was not introduced. As a result of vitamin substitution therapy, the largest reduction in stroke risk was found in cases where the concentration of HCY prior to supplementation had been in the highest range ( $\mathrm{HCY}>13.8 \mu \mathrm{mol} / \mathrm{L}$ ), and in this subgroup the absolute reduction of stroke risk reached $4.1 \%$.

A meta- and stratified analysis ${ }^{81}$ of eight randomized clinical trials of vitamin B confirmed that FA supplementation could significantly reduce the risk of stroke in primary prevention. The reduction in stroke risk was $29 \%$ when FA supplementation exceeded 36 months, $25 \%$ in subjects from regions free from FA fortification, and 25\% among individuals without a history of stroke.

Bazzano et $\mathrm{al}^{82}$ performed a meta-analysis of $12 \mathrm{RCTs}$ that examined the effect of FA supplementation on the risk of CVD, stroke, and all-cause mortality in 16,958 subjects with pre-existing vascular disease. FA supplementation did not reduce the CVD risk or all-cause mortality among participants with a prior history of vascular disease. However, in another meta-analysis of the same trials, Wang et $\mathrm{al}^{81}$ found that the effect of FA supplementation on the outcome of stroke became significant when the Vitamin Intervention for Stroke Prevention trial (VISP) ${ }^{83}$ was excluded. Moreover, the subgroup analysis of these trials showed that the RR for stroke in case of pre-existing CVD was 0.89 , and the RR for stroke with pre-existing endstage renal disease was $0.68 .{ }^{81}$

In the VISP trial, ${ }^{83} 3,680$ adults with non-disabling cerebral infarction were studied. The patients were randomly assigned to high- or low-dose composition of FA, vitamin $\mathrm{B}_{12}$, and vitamin $\mathrm{B}_{6}$. There was a persistent and graded association between the baseline total HCY level and the outcome. Administration of large doses of FA, vitamin $\mathrm{B}_{6}$, and vitamin $B_{12}$, which lowered plasma HCY levels, did not improve survival during a median of 3.2 years of follow-up. However, a $3 \mu \mathrm{mol} / \mathrm{L}$ lower total HCY level was associated with a $10 \%$ lower risk of stroke, a $26 \%$ lower risk of CHD events, and a $16 \%$ lower risk of death in the low-dose group. The subgroup analysis of this trial by Spence and Stampfer ${ }^{84}$ revealed that the incidence of stroke, death, and coronary events decreased by $21 \%$ in the subgroup in which the cases with vitamin $B_{12}$ levels $<250$ or $>637 \mathrm{pmol} / \mathrm{L}$ were excluded.

The Linxian Nutrition Intervention Trial ${ }^{85}$ did not show significant benefit of vitamin supplementation on the risk of death due to cerebrovascular disease until 24 months, but after 6 years of vitamin supplementation the risk reduction reached $37 \%$. This trial represents a good example that shows how short intervention periods with vitamins do not permit definitive conclusions about risk reduction, considering that the process of atherogenesis could take decades from plaque development to clinical events.

A meta-analysis of $13 \mathrm{RCTs}$ by Lee et $\mathrm{al}^{86}$ investigated the effect of FA supplementation on stroke risk in 39,005 subjects. The reduction of stroke events in non-secondary prevention trials was $11 \%$. However, applying a combination of FA plus vitamins $\mathrm{B}_{6}$ and $\mathrm{B}_{12}$ resulted in a $17 \%$ risk reduction. $\mathrm{FA}$ therapy reduced the risk of CVD in patients with advanced chronic kidney disease by $15 \%$, but a greater (better) effect was observed in cases of no FA fortification, or a decrease in HCY levels of $>20 \%{ }^{87}$ In another study, ${ }^{88}$ supplementation with $5 \mathrm{mg}$ FA daily or every other day decreased cardiovascular events in dialysis patients during 871 days of follow-up. This trial showed for the first time that FA therapy decreased cardiovascular events in dialysis patients.

Vitamin B supplements have been shown to reduce the risk of peripheral artery disease (PAD). In a prospective study ${ }^{89}$ of 46,036 male health professionals free of PAD, a $400 \mu \mathrm{g} /$ day FA intake decreased the risk of PAD by $21 \%$. Higher intake of FA $(840 \mu \mathrm{g} /$ day $)$ resulted in a $33 \%$ lower risk compared with those who consumed $244 \mu \mathrm{g} /$ day of FA. ${ }^{89}$

Since vitamin substitution therapies ameliorate many of the parameters indicating the progression of atherosclerosis, it could be expected that their benefit would be reflected in the results of clinical trials. However, it seems that vitamin B complex supplementation was not effective in the prevention of CVD in the majority of the large B vitamin trials. An explanation emerges when examining the design of these trials. It appears that their protocols neglected an essential fact, ie, the impact of confounding factors, for instance: 1) concomitant use of lipid-lowering medications (eg, statins), antiplatelet drugs (eg, aspirin), or other medications; and 2) FA intake, which might have led to bias and inappropriate interpretation of the data. ${ }^{90}$

Moreover, it must be emphasized that large vitamin trials are secondary or tertiary prevention trials, which are not suitable for obtaining correct, results-based conclusions on the primary prevention of CVD. According to a US Preventive Services Task Force (USPSTF) evidence synthesis report:

All trials to date have been of tertiary prevention, and conducted among individuals with prevalent $\mathrm{CHD}$, cerebrovascular disease or diabetes. Whether treatment of elevated HCY levels before an individual develops vascular disease will be beneficial is not resolved by these trials of tertiary prevention. $^{91}$ 


\section{Role of vitamin D in cardiovascular health}

Vitamin D (25-hydroxyvitamin D) is an essential vitamin in bone metabolism; however, there is growing evidence that vitamin $\mathrm{D}$ also plays a key role in maintaining cardiovascular health. The vitamin D receptor ${ }^{92}$ and enzymes for vitamin D metabolism ${ }^{93,94}$ are expressed in vascular and myocardial cells, indicating that vitamin D mediates effects in the cardiovascular system. Vitamin D induces its cardiovascular effects by reducing the activity of the renin-angiotensin system ${ }^{95}$ and inflammation, ${ }^{96}$ by lowering blood pressure, ${ }^{97}$ and reducing the risk of type II diabetes mellitus. ${ }^{98}$ An association has been shown between vitamin D deficiency and CVD, all-cause premature death, heart failure, ${ }^{99}$ coronary artery disease, hypertension, and diabetes mellitus. ${ }^{100}$ In addition, low serum levels of vitamin D - evident in approximately $30 \%$ to $50 \%$ of the general population ${ }^{101,102}$ - are considered to be a risk factor for $\mathrm{CVD}^{103}$ and PAD. ${ }^{104,105}$

In the Framingham Offspring Study, ${ }^{106}$ the rate of major CVD events was $53 \%$ to $80 \%$ higher in subjects with low vitamin D levels. According to the National Health and Nutrition Examination Survey (NHANES) III study, ${ }^{107}$ which had a follow-up of 8.7 years, mortality was inversely associated with vitamin $\mathrm{D}$ levels. This finding is supported by the examination of 10,170 subjects; ${ }^{108}$ by a meta-analysis of 73 cohort studies and $22 \mathrm{RCTs} ;{ }^{109}$ and also by a recent study, ${ }^{110}$ which showed an inverse association between the level of circulating 25-hydroxyvitamin $\mathrm{D}$ and death due to CVD and other causes. In addition, various experimental studies on the effect of vitamin D suggest that vitamin D has a cardioprotective effect. For example, supplementation with vitamin $\mathrm{D}_{3}$ significantly reduced mortality among older adults, ${ }^{109}$ and supplementation with vitamin D improved survival. ${ }^{110}$ An investigation of 17 prospective studies and RCTs suggests that vitamin D supplementation may reduce CVD risk. ${ }^{111}$

Elamin et a ${ }^{112}$ accomplished the meta-analysis of 51 trials on the effect of vitamin D on cardiovascular outcome. A non-significant (4\%) decrease in the risk of death was shown, while no effect on MI and stroke was found. However, if we investigate the pooled results of mortality, in 16 out of 30 trials, ${ }^{112}$ an RR for mortality between 0.28 and 0.94 can be found. The doses of vitamin $\mathrm{D}$ and calcium intake in the examined trials showed significant heterogeneity. In this case, only stratified analysis may result in a more objective evaluation, otherwise the data may be misleading. Moreover, the results may be biased by diseases, old age, intake of medications, and other factors. Another problem with the trials on vitamin $\mathrm{D}$ is that vitamin $\mathrm{D}$ in combination with calcium intake may affect the results, because oral calcium may increase the risk of CVD. ${ }^{113}$ Pilz et al ${ }^{114}$ have summarized the effects of vitamin D on cardiac physiology and its pleiotropic effects on cardiac function and dysfunction, and suggest vitamin D supplementation is appropriate for vitamin D-deficient subjects and for those who are at high risk for myocardial diseases.

ACochrane Review ${ }^{115}$ analyzed 50 trials (94,148 participants) on the effects of vitamin D on mortality and found that vitamin $\mathrm{D}_{3}$ reduced mortality by about $6 \%$, but vitamin $\mathrm{D}_{2}$ (ergocalciferol) as well as alfacalcidol and calcitriol had no significant effect. In an update of the review ${ }^{116}$ the authors also concluded that vitamin $\mathrm{D}_{3}$ decreased mortality in the elderly. Despite these positive results, in a recent "umbrella" review (which investigated 107 systematic reviews, 74 meta-analyses of observational studies, and 87 meta-analyses of RCTs on vitamin $\mathrm{D}$ and multiple health outcomes), the authors found that evidence for a correlation between high $\mathrm{D}$ vitamin levels and low risk of CVD and stroke is only "suggestive" (ie, the association is possible, but not convincing or probable). ${ }^{117}$ Another recent article ${ }^{118}$ states that "at present the data for a causal link between low vitamin D status and CVD are mixed and ambiguous". Kienreich et a ${ }^{103}$ emphasize that while it may be concluded that vitamin D deficiency is an independent risk factor for CVD, the question of whether supplementation has a benefit for cardiovascular outcomes, cannot be answered with certainty.

There are two ongoing RCTs examining the cardiovascular effects of vitamin D supplementation. One is the Vitamin D and Omega 3 Trial (VITAL), ${ }^{119}$ which is a primary prevention trial; the other is the "Role of vitamin D in secondary prevention of cardiovascular events" trial (ClinicalTrials.gov Identifier: NCT01018849). Perhaps the outcome of these trials will provide answers on the question of the role of vitamin $\mathrm{D}$ supplementation in the prevention of CVD.

\section{Conclusion and future perspectives}

The RCTs on vitamins commonly conclude that vitamins are not successful in prevention of CVD. Therefore, vitamin supplementation is not suggested for the aim of prevention. However, this conclusion is not necessarily correct, because it was drawn from the results of secondary prevention trials. Although vitamin supplementation cannot be expected to result in a major decrease of hard cardiovascular endpoints (heart infarct and stroke), it does not mean that vitamin substitutions have no benefit in cardiovascular prevention, especially in primary prevention. There are abundant data from numerous studies suggesting the role of vitamins in 
primary - and even in secondary, eg, stroke - prevention. Considering vitamin supplementation, it should be emphasized that the principal aim is primary prevention, which means the prevention of the first occurrence of MI, stroke, major cardiac event, or death of cardiac origin. However, at a deeper level, the aim of primary prevention is to prevent atherosclerosis, because CVD and its clinical manifestations are due to atherosclerosis. After the vascular bed has undergone atherosclerotic changes, and sclerotic lesions (eg, sclerotic plaques) have appeared, the prevention of CVD as secondary prevention might be considered.

It has been pointed out that vitamins may inhibit atherogenesis at different points and by different mechanisms. There is a postulated mechanism by which vitamins contribute to the prevention of CVD. Antioxidant vitamins - vitamin C, vitamin $\mathrm{E}, \mathrm{FA}$, and vitamin $\mathrm{B}_{6}$ - are capable of decreasing the rate of oxidative stress, which is considered to play a central role in atherogenesis. Vitamin D and FA may inhibit inflammation, which also has an antiatherogenic effect. Vitamin E inhibits platelet aggregation, ${ }^{120}$ interferes with vitamin $\mathrm{K}$ activity, ${ }^{121}$ and may antagonize vitamin $\mathrm{K} .{ }^{122}$ In these scenarios, vitamin E shows similarity to the antiplatelet drug aspirin, which is used for the prevention of both MI and stroke. ${ }^{123}$ Moreover, B vitamins may possess antithrombotic activity by lowering plasma HCY level, which may be very important in hyperhomocysteinemia, as the increased level of HCY is accompanied by a hypercoagulable state ${ }^{124}$ and higher risk of thrombosis. ${ }^{125-127}$ Therefore, lowering the HCY level by $B$ vitamins may attenuate the risk of thrombosis.

Investigating the cause of the conflicting results generated by trials and studies, it may be established that the results depend on the planning, protocol, trial setting, statistical analysis, and other design variables. According to our opinion, the very cause of the differences in the results might be found in the differences in these factors. The treatments, eg, with statins, antiplatelet drugs, vitamins, or other drugs, may cause bias, which brings about changes in the results. Moreover, the results of the primary and secondary prevention trials are often mixed and discussed together (under one umbrella), despite the essential differences in the pathological conditions and backgrounds between them.

The most important future direction in this field of research is - contrary to the usual established methods planning and starting trials on healthy subjects. Most large vitamin trials were conducted for the aim of secondary prevention, and included participants with serious pathological conditions. Therefore, conclusions from these trials and studies cannot be extended to primary prevention, and they are not suitable to settle the question on the effectiveness of vitamins in CVD prevention. The reason physicians do not accept vitamin supplementation as a method of CVD prevention may be that official guidelines do not support the introduction of vitamin substitution. Our conclusion is that vitamin $\mathrm{C}$, vitamin $\mathrm{E}$, vitamin $\mathrm{D}$, and also $\mathrm{B}$ vitamins have beneficial effects on cardiovascular health and prevention of CVD. Whether the combined use of these vitamins is more effective than the use of individual vitamins is a question to be addressed in future research.

\section{Disclosure}

The authors report no conflicts of interest in this work.

\section{References}

1. Ray KK, Kastelein JJ, Boekholdt SM, et al. The ACC/AHA 2013 guideline on the treatment of blood cholesterol to reduce atherosclerotic cardiovascular disease risk in adults: the good the bad and the uncertain: a comparison with ESC/EAS guidelines for the management of dyslipidaemias 2011. Eur Heart J. 2014;35(15):960-968.

2. Sies H, Jones D. Oxidative stress. In: Fink G, editor. Encyclopedia of Stress. San Diego: Elsevier; 2007:45-48.

3. Lugrin J, Rosenblatt-Velin N, Parapanov R, Liaudet L. The role of oxidative stress during inflammatory processes. Biol Chem. 2014;395(2):203-230.

4. Welch GN, Upchurch GR Jr, Loscalzo J. Homocysteine, oxidative stress, and vascular disease. Hosp Pract (1995). 1997;32(6):81-2, 85, 88-92.

5. Outinen PA, Sood SK, Liaw PC, et al. Characterization of the stressinducing effects of homocysteine. Biochem J. 1998;332(Pt 1):213-221.

6. Tyagi N, Sedoris KC, Steed M, Ovechkin AV, Moshal KS, Tyagi SC. Mechanisms of homocysteine-induced oxidative stress. Am J Physiol Heart Circ Physiol. 2005;289(6):H2649-H2656.

7. Au-Yeung KK, Woo CW, Sung FL, Yip JC, Siow YL, O K. Hyperhomocysteinemia activates nuclear factor-kappaB in endothelial cells via oxidative stress. Circ Res. 2004;94(1):28-36.

8. Stampfer MJ, Hennekens CH, Manson JE, Colditz GA, Rosner B, Willett WC. Vitamin E consumption and the risk of coronary disease in women. N Engl J Med. 1993;328(20):1444-1449.

9. Osganian SK, Stampfer MJ, Rimm E, et al. Vitamin C and risk of coronary heart disease in women. $J$ Am Coll Cardiol. 2003;42(2):246-252.

10. Pfister R, Sharp SJ, Luben R, Wareham NJ, Khaw KT. Plasma vitamin $\mathrm{C}$ predicts incident heart failure in men and women in European Prospective Investigation into Cancer and Nutrition-Norfolk prospective study. Am Heart J. 2011;162(2):246-253.

11. Myint PK, Luben RN, Wareham NJ, Khaw KT. Association between plasma vitamin $\mathrm{C}$ concentrations and blood pressure in the European prospective investigation into cancer-Norfolk population-based study Hypertension. 2011;58(3):372-379.

12. Juraschek SP, Guallar E, Appel LJ, Miller ER 3rd. Effects of vitamin C supplementation on blood pressure: a meta-analysis of randomized controlled trials. Am J Clin Nutr. 2012;95(5):1079-1088.

13. Hercberg S, Kesse-Guyot E, Druesne-Pecollo N, et al. Incidence of cancers, ischemic cardiovascular diseases and mortality during 5 -year follow-up after stopping antioxidant vitamins and minerals supplements: a postintervention follow-up in the SU.VI.MAX Study. Int J Cancer 2010;127(8):1875-1881.

14. Rimm EB, Stampfer MJ, Ascherio A, Giovannucci E, Colditz GA, Willett WC. Vitamin E consumption and the risk of coronary heart disease in men. $N$ Engl J Med. 1993;328(20):1450-1456. 
15. Stephens NG, Parsons A, Schofield PM, Kelly F, Cheeseman K, Mitchinson MJ. Randomised controlled trial of vitamin $\mathrm{E}$ in patients with coronary disease: Cambridge Heart Antioxidant Study (CHAOS). Lancet. 1996;347(9004):781-786.

16. Salonen JT, Nyyssönen K, Salonen R, et al. Antioxidant Supplementation in Atherosclerosis Prevention (ASAP) study: a randomized trial of the effect of vitamins $\mathrm{E}$ and $\mathrm{C}$ on 3-year progression of carotid atherosclerosis. J Intern Med. 2000;248(5):377-386.

17. Salonen RM, Nyyssönen K, Kaikkonen J, et al. Six-year effect of combined vitamin $\mathrm{C}$ and $\mathrm{E}$ supplementation on atherosclerotic progression: the Antioxidant Supplementation in Atherosclerosis Prevention (ASAP) Study. Circulation. 2003;107(7):947-953.

18. Boaz M, Smetana S, Weinstein T, et al. Secondary prevention with antioxidants of cardiovascular disease in endstage renal disease (SPACE): randomised placebo-controlled trial. Lancet. 2000;356(9237): $1213-1218$.

19. Kubota Y, Iso H, Date C, et al. Dietary intakes of antioxidant vitamins and mortality from cardiovascular disease: the Japan Collaborative Cohort Study (JACC) study. Stroke. 2011;42(6):1665-1672.

20. Knekt P, Ritz J, Pereira MA, et al. Antioxidant vitamins and coronary heart disease risk: a pooled analysis of 9 cohorts. Am J Clin Nutr. 2004;80(6):1508-1520.

21. Cook NR, Albert CM, Gaziano JM, et al. A randomized factorial trial of vitamins $\mathrm{C}$ and $\mathrm{E}$ and beta carotene in the secondary prevention of cardiovascular events in women: results from the Women's Antioxidant Cardiovascular Study. Arch Intern Med. 2007;167(15): $1610-1618$.

22. Hodis HN, Mack WJ, LaBree L, et al. Serial coronary angiographic evidence that antioxidant vitamin intake reduces progression of coronary artery atherosclerosis. JAMA. 1995;273(23):1849-1854.

23. Ellingsen I, Seljeflot I, Arnesen H, Tonstad S. Vitamin C consumption is associated with less progression in carotid intima media thickness in elderly men: A 3-year intervention study. Nutr Metab Cardiovasc Dis. 2009;19(1):8-14.

24. Yellon DM, Hausenloy DJ. Myocardial reperfusion injury. $N$ Engl J Med. 2007;357(11):1121-1135.

25. Rodrigo R, Cereceda M, Castillo R, et al. Prevention of atrial fibrillation following cardiac surgery: basis for a novel therapeutic strategy based on non-hypoxic myocardial preconditioning. Pharmacol Ther. 2008;118(1):104-127.

26. Rodrigo R, Vinay J, Castillo R, et al. Use of vitamins $\mathrm{C}$ and $\mathrm{E}$ as a prophylactic therapy to prevent postoperative atrial fibrillation. Int $J$ Cardiol. 2010;138(3):221-228.

27. Rodrigo R. Prevention of postoperative atrial fibrillation: novel and safe strategy based on the modulation of the antioxidant system. Front Physiol. 2012;3:93.

28. Rodrigo R, Prieto JC, Castillo R. Cardioprotection against ischaemia/ reperfusion by vitamins $\mathrm{C}$ and $\mathrm{E}$ plus $\mathrm{n}-3$ fatty acids: molecular mechanisms and potential clinical applications. Clin Sci (Lond). 2013;124(1): $1-15$.

29. Rebrova T, Shipulin VM, Afanasiev SA, Vorobieva EV, Kiřko OG. Opyt primeneniia askorbinovoi kisloty kak antioksidanta u patsientov posle operatsii koronarnogo shuntirovaniia s ispol'zovaniem iskusstvennogo krovoobrashcheniia. [The experience of the application of ascorbinic acid as antioxidant after coronary artery surgery with use of cardiopulmonary bypass]. Kardiologiia. 2012;52(7):73-76. Russian.

30. Eslami M, Badkoubeh RS, Mousavi M, et al. Oral ascorbic acid in combination with beta-blockers is more effective than beta-blockers alone in the prevention of atrial fibrillation after coronary artery bypass grafting. Tex Heart Inst J. 2007;34(3):268-274.

31. Papoulidis P, Ananiadou O, Chalvatzoulis E, et al. The role of ascorbic acid in the prevention of atrial fibrillation after elective on-pump myocardial revascularization surgery: a single-center experience a pilot study. Interact Cardiovasc Thorac Surg. 2011;12(2):121-124.

32. Sesso HD, Buring JE, Christen WG, et al. Vitamins E and C in the prevention of cardiovascular disease in men: the Physicians' Health Study II randomized controlled trial. JAMA. 2008;300(18):2123-2133.
33. Gruppo Italiano per lo Studio della Sopravvivenza nell'Infarto miocardico. Dietary supplementation with n-3 polyunsaturated fatty acids and vitamin $\mathrm{E}$ after myocardial infarction: results of the GISSIPrevenzione trial. Lancet. 1999;354(9177):447-455.

34. Lonn E, Bosch J, Yusuf S, et al; HOPE and HOPE-TOO Trial Investigators. Effects of long-term vitamin E supplementation on cardiovascular events and cancer: a randomized controlled trial. JAMA. 2005;293(11):1338-1347.

35. Heart Protection Study Collaborative Group. MRC/BHF Heart Protection Study of antioxidant vitamin supplementation in 20,536 high-risk individuals: a randomised placebo-controlled trial. Lancet. 2002;360(9326):23-33.

36. Lee IM, Cook NR, Gaziano JM, et al. Vitamin E in the primary prevention of cardiovascular disease and cancer: the Women's Health Study: a randomized controlled trial. JAMA. 2005;294(1):56-65.

37. Virtamo J, Rapola JM, Ripatti S, et al. Effect of vitamin E and beta carotene on the incidence of primary nonfatal myocardial infarction and fatal coronary heart disease. Arch Intern Med. 1998;158(6): 668-675.

38. Törnwall ME, Virtamo J, Korhonen PA, et al. Effect of alpha-tocopherol and beta-carotene supplementation on coronary heart disease during the 6-year post-trial follow-up in the ATBC study. Eur Heart J. 2004;25(13):1171-1178.

39. Leppälä JM, Virtamo J, Fogelholm R, et al. Controlled trial of alphatocopherol and beta-carotene supplements on stroke incidence and mortality in male smokers. Arterioscler Thromb Vasc Biol. 2000;20(1): 230-235.

40. Leppälä JM, Virtamo J, Fogelholm R, Albanes D, Taylor PR, Heinonen OP. Vitamin $\mathrm{E}$ and beta carotene supplementation in high risk for stroke: a subgroup analysis of the Alpha-Tocopherol, Beta-Carotene Cancer Prevention Study. Arch Neurol. 2000;57(10):1503-1509.

41. Au-Yeung KK, Yip JC, Siow YL, O K. Folic acid inhibits homocysteineinduced superoxide anion production and nuclear factor kappa B activation in macrophages. Can J Physiol Pharmacol. 2006;84(1):141-147.

42. Shirodaria C, Antoniades C, Lee J, et al. Global improvement of vascular function and redox state with low-dose folic acid: implications for folate therapy in patients with coronary artery disease. Circulation. 2007;115(17):2262-2270

43. Yilmaz H, Sahin S, Sayar N, et al. Effects of folic acid and N-acetylcysteine on plasma homocysteine levels and endothelial function in patients with coronary artery disease. Acta Cardiol. 2007;62(6):579-585.

44. Title LM, Ur E, Giddens K, McQueen MJ, Nassar BA. Folic acid improves endothelial dysfunction in type 2 diabetes - an effect independent of homocysteine-lowering. Vasc Med. 2006;11(2):101-109.

45. Mangoni AA, Sherwood RA, Asonganyi B, Ouldred EL, Thomas S, Jackson SH. Folic acid: a marker of endothelial function in type 2 diabetes? Vasc Health Risk Manag. 2005;1(1):79-83.

46. Das UN. Folic acid says NO to vascular diseases. Nutrition. 2003; 19(7-8):686-692.

47. Bellamy MF, McDowell IF, Ramsey MW, Brownlee M, Newcombe RG, Lewis MJ. Oral folate enhances endothelial function in hyperhomocysteinaemic subjects. Eur J Clin Invest. 1999;29(8):659-662.

48. Guttormsen AB, Ueland PM, Nesthus I, et al. Determinants and vitamin responsiveness of intermediate hyperhomocysteinemia ( $\geq 40$ micromol/liter). The Hordaland Homocysteine Study. J Clin Invest. 1996;98(9):2174-2183.

49. Title LM, Cummings PM, Giddens K, Genest JJ Jr, Nassar BA. Effect of folic acid and antioxidant vitamins on endothelial dysfunction in patients with coronary artery disease. J Am Coll Cardiol. 2000;36(3): 758-765.

50. Moens AL, Vrints CJ, Claeys MJ, Timmermans JP, Champion HC, Kass DA. Mechanisms and potential therapeutic targets for folic acid in cardiovascular disease. Am J Physiol Heart Circ Physiol. 2008;294(5): H1971-H1977.

51. Ji Y, Diao J, Han Y, et al. Pyridoxine prevents dysfunction of endothelial cell nitric oxide production in response to low-density lipoprotein. Atherosclerosis. 2006;188(1):84-94. 
52. Qipshidze N, Tyagi N, Sen U, et al. Folic acid mitigated cardiac dysfunction by normalizing the levels of tissue inhibitor of metalloproteinase and homocysteine-metabolizing enzymes postmyocardial infarction in mice. Am J Physiol Heart Circ Physiol. 2010;299(5):H1484-H1493.

53. Moens AL, Champion HC, Claeys MJ, et al. High-dose folic acid pretreatment blunts cardiac dysfunction during ischemia coupled to maintenance of high-energy phosphates and reduces postreperfusion injury. Circulation. 2008;117(14):1810-1819.

54. Gielis JF, Lin JY, Wingler K, Van Schil PE, Schmidt HH, Moens AL. Pathogenetic role of eNOS uncoupling in cardiopulmonary disorders. Free Radic Biol Med. 2011;50(7):765-776.

55. Stroes ES, van Faassen EE, Yo M, et al. Folic acid reverts dysfunction of endothelial nitric oxide synthase. Circ Res. 2000;86(11):1129-1134.

56. Till U, Röhl P, Jentsch A, et al. Decrease of carotid intima-media thickness in patients at risk to cerebral ischemia after supplementation with folic acid, Vitamins B6 and B12. Atherosclerosis. 2005;181(1):131-135.

57. Ntaios G, Savopoulos C, Karamitsos D, et al. The effect of folic acid supplementation on carotid intima-media thickness in patients with cardiovascular risk: a randomized, placebo-controlled trial. Int J Cardiol. 2010;143(1):16-19.

58. Qin X, Xu M, Zhang Y, et al. Effect of folic acid supplementation on the progression of carotid intima-media thickness: a meta-analysis of randomized controlled trials. Atherosclerosis. 2012;222(2): 307-313.

59. Marcucci R, Zanazzi M, Bertoni E, et al. Vitamin supplementation reduces the progression of atherosclerosis in hyperhomocysteinemic renal-transplant recipients. Transplantation. 2003;75(9):1551-1555.

60. Tungkasereerak P, Ong-ajyooth L, Chaiyasoot W, et al. Effect of shortterm folate and vitamin B supplementation on blood homocysteine level and carotid artery wall thickness in chronic hemodialysis patients. J Med Assoc Thai. 2006;89(8):1187-1193.

61. Hodis HN, Mack WJ, Dustin L, et al. High-dose B vitamin supplementation and progression of subclinical atherosclerosis: a randomized controlled trial. Stroke. 2009;40(3):730-736.

62. Voutilainen S, Rissanen TH, Virtanen J, Lakka TA, Salonen JT; Kuopio Ischemic Heart Disease Risk Factor Study Group. Low dietary folate intake is associated with an excess incidence of acute coronary events: the Kuopio Ischemic Heart Disease Risk Factor Study. Circulation 2001;103(22):2674-2680.

63. Bazzano LA, He J, Ogden LG, et al. Dietary intake of folate and risk of stroke in US men and women: NHANES I Epidemiologic Follow-up Study. National Health and Nutrition Examination Survey. Stroke. 2002;33(5):1183-1188.

64. Voutilainen S, Virtanen JK, Rissanen TH, et al. Serum folate and homocysteine and the incidence of acute coronary events: the Kuopio Ischaemic Heart Disease Risk Factor Study. Am J Clin Nutr. 2004;80(2): 317-323.

65. Imamura A, Murakami R, Takahashi R, et al. Low folate levels may be an atherogenic factor regardless of homocysteine levels in young healthy nonsmokers. Metabolism. 2010;59(5):728-733.

66. Giles WH, Kittner SJ, Anda RF, Croft JB, Casper ML. Serum folate and risk for ischemic stroke. First National Health and Nutrition Examination Survey epidemiologic follow-up study. Stroke. 1995;26(7): 1166-1170.

67. Albert CM, Cook NR, Gaziano JM, et al. Effect of folic acid and $\mathrm{B}$ vitamins on risk of cardiovascular events and total mortality among women at high risk for cardiovascular disease: a randomized trial. JAMA. 2008;299(17):2027-2036.

68. Bentley TG, Weinstein MC, Willett WC, Kuntz KM. A cost-effectiveness analysis of folic acid fortification policy in the United States. Public Health Nutr. 2009;12(4):455-467.

69. Antoniades C, Antonopoulos AS, Tousoulis D, Marinou K, Stefanadis C. Homocysteine and coronary atherosclerosis: from folate fortification to the recent clinical trials. Eur Heart J. 2009;30(1):6-15.

70. Rimm EB, Willett WC, Hu FB, et al. Folate and vitamin B6 from diet and supplements in relation to risk of coronary heart disease among women. JAMA. 1998;279(5):359-364.
71. Holmquist C, Larsson S, Wolk A, de Faire U. Multivitamin supplements are inversely associated with risk of myocardial infarction in men and women - Stockholm Heart Epidemiology Program (SHEEP). J Nutr. $2003 ; 133(8): 2650-2654$.

72. Rautiainen S, Akesson A, Levitan EB, Morgenstern R, Mittleman MA, Wolk A. Multivitamin use and the risk of myocardial infarction: a population-based cohort of Swedish women. Am J Clin Nutr. 2010;92(5):1251-1256.

73. He K, Merchant A, Rimm EB, et al. Folate, vitamin B6, and B12 intakes in relation to risk of stroke among men. Stroke. 2004;35(1):169-174.

74. Larsson SC, Männistö S, Virtanen MJ, Kontto J, Albanes D, Virtamo J. Folate, vitamin B6, vitamin B12, and methionine intakes and risk of stroke subtypes in male smokers. Am J Epidemiol. 2008;167(8): 954-961.

75. Bønaa KH, Njølstad I, Ueland PM, et al; NORVIT Trial Investigators. Homocysteine lowering and cardiovascular events after acute myocardial infarction. $N$ Engl J Med. 2006;354(15): $1578-1588$

76. Armitage JM, Bowman L, Clarke RJ, et al; Study of the Effectiveness of Additional Reductions in Cholesterol and Homocysteine (SEARCH) Collaborative Group. Effects of homocysteine-lowering with folic acid plus vitamin B12 vs placebo on mortality and major morbidity in myocardial infarction survivors: a randomized trial. JAMA. 2010;303(24):2486-2494

77. Ebbing M, Bleie Ø, Ueland PM, et al. Mortality and cardiovascular events in patients treated with homocysteine-lowering B vitamins after coronary angiography: a randomized controlled trial. JAMA. 2008;300(7):795-804.

78. Lonn E, Yusuf S, Arnold MJ, et al; Heart Outcomes Prevention Evaluation (HOPE) 2 Investigators. Homocysteine lowering with folic acid and B vitamins in vascular disease. $N$ Engl J Med. 2006;354(15): 1567-1577.

79. Jamison RL, Hartigan P, Kaufman JS, et al. Effect of homocysteine lowering on mortality and vascular disease in advanced chronic kidney disease and end-stage renal disease: a randomized controlled trial. JAMA. 2007;298(10):1163-1170.

80. Saposnik G, Ray JG, Sheridan P, et al; Heart Outcomes Prevention Evaluation 2 Investigators. Homocysteine-lowering therapy and stroke risk, severity, and disability: additional findings from the HOPE 2 trial. Stroke. 2009;40(4):1365-1372.

81. Wang X, Qin X, Demirtas H, et al. Efficacy of folic acid supplementation in stroke prevention: a meta-analysis. Lancet. 2007;369(9576): 1876-1882.

82. Bazzano LA, Reynolds K, Holder KN, He J. Effect of folic acid supplementation on risk of cardiovascular diseases: a meta-analysis of randomized controlled trials. JAMA. 2006;296(22):2720-2726.

83. Toole JF, Malinow MR, Chambless LE, et al. Lowering homocysteine in patients with ischemic stroke to prevent recurrent stroke, myocardial infarction, and death: the Vitamin Intervention for Stroke Prevention (VISP) randomized controlled trial. JAMA. 2004;291(5): $565-575$.

84. Spence JD, Stampfer MJ. Understanding the complexity of homocysteine lowering with vitamins: the potential role of subgroup analyses. JAMA. 2011;306(23):2610-2611

85. Mark SD, Wang W, Fraumeni JF Jr, et al. Lowered risks of hypertension and cerebrovascular disease after vitamin/mineral supplementation: the Linxian Nutrition Intervention Trial. Am J Epidemiol. 1996;143(7): 658-664.

86. Lee M, Hong KS, Chang SC, Saver JL. Efficacy of homocysteinelowering therapy with folic acid in stroke prevention: a meta-analysis. Stroke. 2010;41(6):1205-1212.

87. Qin X, Huo Y, Langman CB, et al. Folic acid therapy and cardiovascular disease in ESRD or advanced chronic kidney disease: a meta-analysis. Clin J Am Soc Nephrol. 2011;6(3):482-488

88. Righetti M, Serbelloni P, Milani S, Ferrario G. Homocysteine-lowering vitamin B treatment decreases cardiovascular events in hemodialysis patients. Blood Purif. 2006;24(4):379-386. 
89. Merchant AT, Hu FB, Spiegelman D, Willett WC, Rimm EB, Ascherio A. The use of B vitamin supplements and peripheral arterial disease risk in men are inversely related. J Nutr. 2003;133(9):2863-2867.

90. Debreceni B, Debreceni L. Why do homocysteine-lowering B vitamin and antioxidant $\mathrm{E}$ vitamin supplementations appear to be ineffective in the prevention of cardiovascular diseases? Cardiovasc Ther. 2012;30(4): 227-233.

91. Helfand M, Buckley D, Fleming C, et al. Screening for Intermediate Risk Factors for Coronary Heart Disease: Systematic Evidence Synthesis. Evidence Synthesis No. 73. AHRQ Publication No. 10-05141-EF-1. Rockville, Maryland: Agency for Healthcare Research and Quality; 2009. Available from: http://www.ncbi.nlm.nih.gov/ books/NBK35208. Accessed August 26, 2014.

92. Fraga C, Blanco M, Vigo E, Segura C, García-Caballero T, PérezFernández R. Ontogenesis of the vitamin D receptor in rat heart. Histochem Cell Biol. 2002;117(6):547-550.

93. Tishkoff DX, Nibbelink KA, Holmberg KH, Dandu L, Simpson RU. Functional vitamin D receptor (VDR) in the t-tubules of cardiac myocytes: VDR knockout cardiomyocyte contractility. Endocrinology. 2008;149(2):558-564.

94. Zhou C, Lu F, Cao K, Xu D, Goltzman D, Miao D. Calcium-independent and 1,25(OH)2D3-dependent regulation of the renin-angiotensin system in 1alpha-hydroxylase knockout mice. Kidney Int. 2008;74(2): $170-179$

95. de Borst MH, Vervloet MG, ter Wee PM, Navis G. Cross talk between the renin-angiotensin-aldosterone system and vitamin D-FGF-23klotho in chronic kidney disease. J Am Soc Nephrol. 2011;22(9): 1603-1609.

96. Schleithoff SS, Zittermann A, Tenderich G, Berthold HK, Stehle P, Koerfer R. Vitamin D supplementation improves cytokine profiles in patients with congestive heart failure: a double-blind, randomized, placebo-controlled trial. Am J Clin Nutr. 2006;83(4):754-759.

97. Krause R, Bühring M, Hopfenmüller W, Holick MF, Sharma AM. Ultraviolet B and blood pressure. Lancet. 1998;352(9129): 709-710.

98. Pittas AG, Dawson-Hughes B, Li T, et al. Vitamin D and calcium intake in relation to type 2 diabetes in women. Diabetes Care. 2006;29(3): 650-656.

99. Liu L, Chen M, Hankins SR, et al; Drexel Cardiovascular Health Collaborative Education, Research, and Evaluation Group. Serum 25-hydroxyvitamin D concentration and mortality from heart failure and cardiovascular disease, and premature mortality from all-cause in United States adults. Am J Cardiol. 2012;110(6):834-839.

100. Michos ED, Melamed ML. Vitamin D and cardiovascular disease risk. Curr Opin Clin Nutr Metab Care. 2008;11(1):7-12.

101. Lee JH, O’Keefe JH, Bell D, Hensrud DD, Holick MF. Vitamin D deficiency an important, common, and easily treatable cardiovascular risk factor? J Am Coll Cardiol. 2008;52(24):1949-1956.

102. Tangpricha V, Pearce EN, Chen TC, Holick MF. Vitamin D insufficiency among free-living healthy young adults. Am J Med. 2002;112(8):659-662.

103. Kienreich K, Tomaschitz A, Verheyen N, et al. Vitamin D and cardiovascular disease. Nutrients. 2013;5(8):3005-3021.

104. Chua GT, Chan YC, Cheng SW. Vitamin D status and peripheral arterial disease: evidence so far. Vasc Health Risk Manag. 2011;7: 671-675.

105. van de Luijtgaarden KM, Voûte MT, Hoeks SE, et al. Vitamin D deficiency may be an independent risk factor for arterial disease. Eur J Vasc Endovasc Surg. 2012;44(3):301-306.

106. Wang TJ, Pencina MJ, Booth SL, et al. Vitamin D deficiency and risk of cardiovascular disease. Circulation. 2008;117(4):503-511.

107. Melamed ML, Michos ED, Post W, Astor B. 25-hydroxyvitamin D levels and the risk of mortality in the general population. Arch Intern Med. 2008;168(15):1629-1637.
108. Amer M, Qayyum R. Relationship between 25-hydroxyvitamin D and all-cause and cardiovascular disease mortality. Am J Med. 2013;126(6): 509-514.

109. Chowdhury R, Kunutsor S, Vitezova A, et al. Vitamin D and risk of cause specific death: systematic review and meta-analysis of observational cohort and randomised intervention studies. BMJ. 2014;348g1903.

110. Vacek JL, Vanga SR, Good M, Lai SM, Lakkireddy D, Howard PA. Vitamin D deficiency and supplementation and relation to cardiovascular health. Am J Cardiol. 2012;109(3):359-363.

111. Wang L, Manson JE, Song Y, Sesso HD. Systematic review: vitamin D and calcium supplementation in prevention of cardiovascular events. Ann Intern Med. 2010;152(5):315-323.

112. Elamin MB, Abu Elnour NO, Elamin KB, et al. Vitamin D and cardiovascular outcomes: a systematic review and meta-analysis. J Clin Endocrinol Metab. 2011;96(7):1931-1942.

113. Bolland MJ, Grey A, Avenell A, Gamble GD, Reid IR. Calcium supplements with or without vitamin D and risk of cardiovascular events: reanalysis of the Women's Health Initiative limited access dataset and meta-analysis. BMJ. 2011;342:d2040.

114. Pilz S, Tomaschitz A, Drechsler C, Dekker JM, März W. Vitamin D deficiency and myocardial diseases. Mol Nutr Food Res. 2010;54(8): 1103-1113.

115. Bjelakovic G, Gluud LL, Nikolova D, et al. Vitamin D supplementation for prevention of mortality in adults. Cochrane Database Syst Rev. 2011;7:CD007470.

116. Bjelakovic G, Gluud LL, Nikolova D, et al. Vitamin D supplementation for prevention of mortality in adults. Cochrane Database Syst Rev. 2014;1:CD007470.

117. Theodoratou E, Tzoulaki I, Zgaga L, Ioannidis JP. Vitamin D and multiple health outcomes: umbrella review of systematic reviews and meta-analyses of observational studies and randomised trials. $B M J$. 2014;348:g2035.

118. Cashman KD. A review of vitamin D status and CVD. Proc Nutr Soc. 2014;73(1):65-72.

119. Manson JE, Bassuk SS, Lee IM, et al. The VITamin D and OmegA-3 TriaL (VITAL): rationale and design of a large randomized controlled trial of vitamin D and marine omega-3 fatty acid supplements for the primary prevention of cancer and cardiovascular disease. Contemp Clin Trials. 2012;33(1):159-171.

120. Freedman JE, Farhat JH, Loscalzo J, Keaney JF Jr. Alpha-tocopherol inhibits aggregation of human platelets by a protein kinase $\mathrm{C}$-dependent mechanism. Circulation. 1996;94(10):2434-2440.

121. Traber MG. Vitamin E and K interactions - a 50-year-old problem. Nutr Rev. 2008;66(11):624-629.

122. Booth SL, Golly I, Sacheck JM, et al. Effect of vitamin E supplementation on vitamin $\mathrm{K}$ status in adults with normal coagulation status. Am J Clin Nutr. 2004;80(1):143-148.

123. Hennekens $\mathrm{CH}$. Update on aspirin in the treatment and prevention of cardiovascular disease. Am J Manag Care. 2002;8(Suppl 22): S691-S700.

124. Ogawa M, Abe S, Saigo M, et al. Homocysteine and hemostatic disorder as a risk factor for myocardial infarction at a young age. Thromb Res. 2003;109(5-6):253-258.

125. Rodgers GM, Kane WH. Activation of endogenous factor V by a homocysteine-induced vascular endothelial cell activator. J Clin Invest. 1986;77(6):1909-1916.

126. Rodgers GM, Conn MT. Homocysteine, an atherogenic stimulus, reduces protein $\mathrm{C}$ activation by arterial and venous endothelial cells. Blood. 1990;75(4):895-901.

127. Ridker PM, Hennekens CH, Selhub J, Miletich JP, Malinow MR, Stampfer MJ. Interrelation of hyperhomocyst(e)inemia, factor V Leiden, and risk of future venous thromboembolism. Circulation. 1997;95(7):1777-1782. 
Research Reports in Clinical Cardiology

Dovepress

\section{Publish your work in this journal}

Research Reports in Clinical Cardiology is an international, peerreviewed, open access journal publishing original research, reports, editorials, reviews and commentaries on all areas of cardiology in the clinic and laboratory. The manuscript management system is completely online and includes a very quick and fair peer-review system.

Visit http://www.dovepress.com/testimonials.php to read real quotes from published authors.

Submit your manuscript here: http://www.dovepress.com/research-reports-in-clinical-cardiology-journal 